\title{
Chemokine Measurement
}

National Cancer Institute

\section{Source}

National Cancer Institute. Chemokine Measurement. NCI Thesaurus. Code C81867.

The determination of the amount of chemokine present in a sample. 